\title{
НЕДОСТАТКИ АНАЛИЗА ФИНАНСОВОЙ ОТЧЕТНОСТИ КОММЕРЧЕСКИХ ПРЕДПРИЯТИЙ
}

\author{
(C) 2021 Тагирова Диана Рустемовна \\ магистр экономики \\ Санкт-Петербургский государственный экономический университет, Россия, Санкт-Петербург \\ E-mail: di.tagirova2016@yandex.ru
}

Применение современных способов и приемов анализа финансовой отчетности коммерческих предприятий позволяет более детально изучить финансовое положение и финансовое состояние организации. Исходя из этого, автор выявляет недостатки анализа РСБУ и МСФО. Объектом исследования являются ведущие предприятий Российской Федерации и крупные международные холдинги (для сравнительного анализа финансовой отчетности, составленной по различным стандартам и выявления недостатков).

Ключевые слова: экономический анализ, недостатки, эффективность, МСФО, РСБУ, аналитика, методы анализа.

В условиях развития экономических процессов в мире, глобализации экономических систем целесообразно определить методологическую базу аналитических процедур, которая будет актуальной и эффективной, а также соответствовать современным тенденциям экономического роста, главной целью которой будет повышение эффективности и обоснование управленческих решений внутри предприятий, а также повышение инвестиционной привлекательности фирмы.

Обоснование управленческих решений в целях повышения эффективности деятельности предприятия с помощью аналитического процесса - является основной целью экономического анализа, представляющего собой сложную систему взаимосвязанных процессов, включающих различные виды анализа, методов и этапов его проведения.

Под экономическим анализом понимается совокупность процедур описания и последующей систематизации процессов развития экономики в целом и отдельных ее частей, а также для исследования экономических моделей на макроуровне. Можно выделить работы таких ученых, как Й.Шумпетер, П. Самуэльсон, Р. Познер и т.д. Среди российских ученых, кто внес наибольший вклад в развитие такой науки, как экономический анализ, можно выделить 3. П.Евзлина, А.П. Рудановского, Н.А. Кипарисова, Я.М.Гальперина и других. Одним из ведущих направлений экономического анализа является финансовый анализ, который зародился в России как новое научное направление - балансоведение. В дальнейшим российский финансовый анализ

«балансоведение» начал дополняться техникоэкономическим анализом, основная цель которого состоит в систематизированном изложении методов и техник аналитических расчетов на уровне всего предприятия, а не только финансового блока.

В статье рассматривается анализ финансовой отчетности, как составляющей экономического анализа. Анализ финансовой отчетности позволяет провести оценку: текущего финансового состояния предприятия (т.е. оценка принадлежащих предприятию активов и обязательств); стадии производственного/операционного цикла; прогнозных значений и направлений дальнейшего развития предприятия. Методология экономического анализа представляет собой совокупность приемов и способов оценки финансовых показателей предприятий.

Среди общих проблем анализа финансовой отчетности в российской практике можно выделить четыре группы: 1 . Проблема достоверности проведенного анализа; 2. Проблема оценки финансового положения; 3. Непрерывность функционирования; 4. Проблема «полноты» информации.

1) Проблема достоверности проведенного анализа.

Достоверность отраженных фактов хозяйственной деятельности - один из главных критериев проведения анализа финансовой отчетности. Стоит отметить, что такой вид экономического анализа - ограничен, поскольку, во-первых, информация может быть недостоверной (как было упомянуто), а во-вторых, фи- 
нансовый анализ - наука более творческая, и соответственно «не совсем» точная наука, поскольку анализ финансовой отчетности служит в большей степени не для точных и окончательных ответов, а для постановки вопросов и качественной оценки возможностей экономического субъекта.

Применяемые методы учета и отчетности не отражают реальную экономическую картину в реальном времени. Например, отчетность составлена на конец отчетного периода (31 декабря), а на сегодняшний день - информация не будет актуальной. Кроме того, существуют различные методы учета, например затрат, учета МПЗ и т.д. Данные различия могут затруднить процесс сопоставления результатов анализа между компаниями одной отрасли.

2) Проблемы оценки финансового положения.

При анализе финансового положения возникают ряд проблем:

- оценка активов. Как правило, активы отражаются в учете и отчетности по исторической стоимости или по цене приобретения (в отчётности за вычетом амортизации). Однако действительная стоимость может изменяться вследствие инфляции или дефляции, т.е. возникает разница между учетной и текущей стоимостью;

- собственный капитал предприятия можно рассматривать как с учетной точки зрения, т.е. как включающий в себя вложения собственников предприятия и нераспределенную прибыль, так и с финансовой точки зрения, как разницу стоимости активов и долевых обязательств. Рассмотрение собственного капитала с финансовой точки зрения предполагает необходимость учета активов по рыночной стоимости;

- показатели ликвидности. Основная проблема, связанная с ликвидностью - понятие «текущий статус актива». По определению, ликвидность - это способность предприятия «превратить» текущие активы в денежные средства для погашения своей задолженности.

3) Непрерывность функционирования.

Непрерывность функционирования предполагает, что предприятие существует юридически и действует в течение времени использования своих активов по назначению и, соответственно, погашает обязательства в рамках своей хозяйственной деятельности. В период его функционирования с той или иной вероятностью возможно возникновение ситуации банкротства, что требует определения, в первую очередь, достоверности оценки активов предприятия, а также адекватности величины собственного капитала в сложившейся ситуации. В такой ситуации предприятия реализует свои активы для одной цели - погасить задолженность перед своими контрагентами.

4) Проблема «полноты» информации.

Для более качественного анализа, например выручки от продаж, недостаточно просто сравнить план-факт и результаты прошлых периодов. При наличии полной информации можно проанализировать выполнение плана и получение выручки в ассортиментном разрезе, по местам реализации и т.д.

Прежде всего, необходимо отметить, что РСБУ не содержит большого количества информации и руководств по учету процентов, роялти и дивидендов в соответствии с МСФО. В Приложении к МСФО (IAS) 18 представлена более подробная информация о видах комиссий за финансовые услуги. Как обычно, по РСБУ требуются документы, подтверждающие, что предприятие имеет право на получение экономических выгод.

Существенное различие между МСФО (IAS) 18 и ПБУ 9/99 заключается в том, что РСБУ позволяет выбирать между двумя методами признания выручки - методом выполненного контракта и методом процента выполнения. Хотя метод процента выполнения считается приоритетным, у российских бухгалтеров есть возможность выбрать один из этих двух или даже применить разные методы к одному контракту в один и тот же отчетный период, если это необходимо. В свою очередь, МСФО не позволяют использовать метод завершенного договора.

В настоящее время в Российской Федерации большое количество разных систем мониторинга хозяйственной деятельности предприятий базируется на применении коэффициентного анализа. Ряд существенных недостатков коэффициентного анализа финансовой отчетности, на наш взгляд следующие:

Во-первых, это большое количество всех возможных коэффициентов, а это, в свою очередь, значительно затрудняет оценку финансового анализа предприятия, а также поиски и реализацию управленческих решений.

Во-вторых, это сложность обоснованного нормирования коэффициентов. Иными словами, аналитик затрудняется интерпретировать проведенный коэффициентный анализ с точки зрения выбранных нормативов, поскольку база 
нормативных показателей по оценке финансового положения предприятий в Российской Федерации недостаточна развита, а доступ к имеющимся среднеотраслевым стандартам или нормативам ограничен.

И, в-третьих, все коэффициенты в разных источниках (учебники для ВУЗов, статьи, научные публикации, нормативно-правовые источники и т.д.) дают совершенно разные названия одним и тем же коэффициентам и, кроме того, зачастую они имеют разные формулы расчетов.

На мой взгляд, также можно отнести к недостаткам анализа финансовой отчетности в России тот факт, что анализ российской финансовой отчетности и отчетности по международным стандартам различается. Это происходит за счет различных подходов к учету активов и обязательств в РСБУ и МСФО. Также необходимо отметить, что отчетность, составленная по МСФО - более востребованная и актуальная для потенциальных инвесторов, нежели отчетность, составленная по РСБУ. Это связано с тем, что российская отчетность составляется для налоговых органов, для контроля со стороны государства, а отчетность по МСФО в свою очередь составляется для инвесторов, для их привлечения. И поэтому, анализ финансовой отчетности по международным стандартам - будет более достоверным и актуальным.

На примере признания выручки особенно заметны различия в МСФО и РСБУ. Прежде всего, различия в критериях признания выручки, в частности критерий РСБУ о том, что организация должна иметь право при получении, что подтверждается конкретным контрактом или другим соответствующим документом. В МСФО нет такого условия, потому что Концепция требует использовать допущение о содержании, а не форме, которое гласит: «Если информация должна достоверно отражать операции и другие события, которые она призвана представлять, необходимо, чтобы они были учтены и представлены в соответствии с их сущностью и экономической реальностью, а не только их юридической формой». РСБУ требует признавать выручку, когда передача права собственности официально задокументирована надлежащим образом, в МСФО приводятся точные ситуации и примеры, которые помогают определить, были ли переданы риски и выгоды или нет, и которые также могут быть подтверждены не документами, а результатом профессионального суждения.

В то время как в соответствии с РСБУ выручка признается исходя из общей торговой дебиторской задолженности покупателя без учета дисконтирования. МСФО дает гораздо более подробные инструкции по оценке выручки, объясняя, что такое справедливая стоимость, и, если есть отсроченная выручка, как именно ее следует дисконтировать. В то время как РСБУ вообе не использует дисконтирование отложенного возмещения, вместо этого признавая выручку в сумме денежных средств или дебиторской задолженности, которая указана в контракте, то есть в цене контракта.

Приведем практический пример некоторых аналитических процедур по отношению к отчетности, составленной по РСБУ и МСФО. Финансовый анализ проведен по отчетности компании ПАО «Газпром» за 2019-2020 гг.

В таблице 1 представлен расчет рентабельности продаж по отчетности РСБУ и в таблице 2 - отчетность по МСФО.

Как видно из приведенных таблиц, значение и динамика показателя рентабельности продаж - отличается, в особенности динамика данного показателя по сравнению с 2019 годом. Согласно отчетности по РСБУ, рентабельность продаж снизилась на 2,89\%; согласно отчетности по МСФО, рентабельность снизилась на 8,85\%.

Таблица 1. Расчет рентабельности продаж по отчетности РСБУ

\begin{tabular}{|l|c|c|c|}
\hline \multicolumn{1}{|c|}{ Показатели } & 2019 & 2020 & $\begin{array}{c}\text { Абсолютное } \\
\text { отклонение }\end{array}$ \\
\hline \multicolumn{1}{|c|}{1} & 2 & 3 & 4 \\
\hline 1. Выручка, тыс.руб. & 8325008 & 7813329 & -511679 \\
\hline 2. Себестоимость, тыс.руб. & 6319904 & 6142898 & -177006 \\
\hline 3. Коммерческие расходы, тыс.руб. & 757 & 832 & 75 \\
\hline 4. Управленческие расходы, тыс.руб. & 369151 & 360365 & -8786 \\
\hline 5. Прибыль от продаж, тыс.руб. & 1635196 & 1309234 & -325962 \\
\hline 6. Рентабельность продаж, \% & 19,64 & 16,76 & $-2,89$ \\
\hline
\end{tabular}

Источник: составлено автором по отчетности ПАО «Газпром» 
Таблица 2. Расчет рентабельности продаж по отчетности МСФо

\begin{tabular}{|l|c|c|c|}
\hline \multicolumn{1}{|c|}{ Показатели } & 2019 & 2020 & $\begin{array}{c}\text { Абсолютное } \\
\text { отклонение }\end{array}$ \\
\hline \multicolumn{1}{|c|}{1} & 2 & 3 & 4 \\
\hline 1. Выручка, тыс.руб. & 8224177 & 7659623 & -564554 \\
\hline 2. Операционные расходы, тыс.руб. & 6181191 & 6387071 & 205880 \\
\hline 3. Доход или расход по торговым операциям, тыс.руб. & 18015 & 24957 & 6942 \\
\hline 4. Обесценение фин. активов, тыс.руб. & 130971 & 127738 & -3233 \\
\hline 5. Прибыль от продаж, тыс.руб. & 1930030 & 1119857 & -810173 \\
\hline 6. Рентабельность продаж, \% & 23,47 & 14,62 & $-8,85$ \\
\hline
\end{tabular}

Источник: составлено автором по отчетности ПАО «Газпром»

Разница между двумя показателями - примерно в $6 \%$, что в относительном выражении имеет весомое значение.

Также в качестве практического примера рассмотрим анализ платежеспособности ПАО «Газпром» и сравним полученные результаты. В таблице 3 представлен расчет показателей платежеспособности по отчетности, составленной по РСБУ, а в таблице 4 - по отчетности, составленной по МСФО.

Как видно из приведенного анализа отчетностей по РСБУ и МСФО, различия также очевидны. Все показатели ликвидности, рассчитанные по отчетности, составленной по РСБУ, - значительно завышены по сравнению с показателями ликвидности, рассчитанными по отчетности, составленной в соответствии с МСФО. Если сравнивать динамику данных показателей - то в данном случае она «примерно» одинакова. Именно поэтому аналитику важно понимать и знать основные отличия и сходства российских стандартов бухгалтерского учета и международных стандартов, чтобы сделать правильные выводы и рекомендации для руководства предприятия.

В будущей исследовательской работе я буду более подробно рассматривать данный вопрос; можно применить более детальную методику анализа финансовой отчетности к РСБУ и МСФО в целях оценки инвестиционной привлекательности компании, а также определить оптимальный инструментарий между данными видами отчетности. В этом есть необходимость, потому что как уже отмечалось, основное различие МСФО и РСБУ - это ключевой пользователь финансовой отчетности. Тот факт, что РСБУ нацелены в основном на органы власти как на ключевого пользователя финансовой информации, подразумевает множество основополагающих допущений и принципов. Эти базовые допущения и принципы могут выглядеть так же, как и в МСФО, но на практике реализуются другими способами. Соответственно, необходимо подчеркнуть важность подтверждающих документов (контракты, первичные документы, такие как счета-фактуры, акты приема-передачи и т.д.) при отражении операций в РСБУ. МСФО больше полагаются на профессиональное суждение бухгалтера и руководствуются принципом - содержание важнее формы, в то время как в России ведение бухгалтерского учета и подготовка финансовой отчетности основываются на инструктивных положениях и требованиях регулирующих органов.

Таблица 3. Расчет показателей платежеспособности по отчетности РСБУ

\begin{tabular}{|l|c|c|c|}
\hline \multicolumn{1}{|c|}{ Показатели } & 2019 & 2020 & $\begin{array}{c}\text { Абсолютное } \\
\text { отклонение }\end{array}$ \\
\hline 1. Денежные средства, тыс.руб. & 861407 & 699948 & -161459 \\
\hline 2. Краткосрочные финансовые вложения, тыс.руб. & 890386 & 827377 & -63009 \\
\hline 3. Краткосрочная дебиторская задолженность, тыс.руб. & 1514133 & 1329229 & -184904 \\
\hline 4. Запасы, тыс.руб. & 979226 & 1014285 & 35059 \\
\hline 5. Краткосрочные обязательства, тыс.руб. & 2399998 & 2401324 & 1326 \\
\hline 6. Коэф абсолютной ликвидности ((1+2)/5), \% & 0,73 & 0,64 & $-0,09$ \\
\hline 7. Коэф промежуточной ликвидности ((1+2+3)/5), \% & 1,36 & 1,19 & $-0,17$ \\
\hline 8. Коэф покрытия ((1+2+3+4)/5), \% & 1,77 & 1,61 & $-0,16$ \\
\hline
\end{tabular}

Источник: составлено автором по отчетности ПАО «Газпром» 
Таблица 4. Расчет показателей платежеспособности по отчетности МСФО

\begin{tabular}{|l|c|c|c|}
\hline \multicolumn{1}{|c|}{ Показатели } & 2019 & 2020 & $\begin{array}{c}\text { Абсолютное } \\
\text { отклонение }\end{array}$ \\
\hline 1. Денежные средства, тыс.руб. & 849419 & 696057 & -153362 \\
\hline 2. Краткосрочные финансовые вложения, тыс.руб. & 26859 & 57571 & 30712 \\
\hline 3. Краткосрочная дебиторская задолженность, тыс.руб. & 1222735 & 1040340 & -182395 \\
\hline 4. Запасы, тыс.руб. & 909677 & 946361 & 36684 \\
\hline 5. Краткосрочные обязательства, тыс.руб. & 2473695 & 2527476 & 53781 \\
\hline 6. Коэф абсолютной ликвидности ((1+2)/5), \% & 0,35 & 0,30 & $-0,06$ \\
\hline 7. Коэф промежуточной ликвидности ((1+2+3)/5), \% & 0,85 & 0,71 & $-0,14$ \\
\hline 8. Коэф покрытия $((1+2+3+4) / 5), \%$ & 1,22 & 1,08 & $-0,13$ \\
\hline
\end{tabular}

Источник: составлено автором по отчетности ПАО «Газпром»

\section{Библиографический список}

1. Altman E.I., Marco G., Varetto F. (1994): Corporate Distress Diagnosis: Comparisons using Linear Discriminant Analysis And Neural Network (the Italian Experience) // J. Of Banking and Finance. Vol 18 № 3.

2. Аренс Э.А., Лоббек Дж. К. Аудит. Перевод М.А. Терехова: учебное пособие.- Москва: Финансы и статистика, 2003. - $550 \mathrm{c}$.

3. Басовский Л.Е., Лунева А.М., Басовский А. Л. Экономический анализ (Комплексный экономический анализ хозяйственной деятельности): учебное пособие.- Москва: ИНФРА-М, 2007.- 222 с.

4. Бикбулатов А.А., Хапугина Л. С. Особенности методологии анализа финансовой отчетности. Казанский экономический вестник, 2018. № 4(36). С. 101-108.

5. Герасимов Б.И., Коновалова Т.М., Спиридонов С.П. Экономический анализ: Учеб. пособие. В 2 ч. Тамбов: Изд-во: Тамб. гос. техн. ун-та, 2004. Ч. 1. 64 с.

6. Ковалев В.В. Методы оценки инвестиционных проектов - М: Финансы и статистика, 1998-144 с

7. Ковалев В.В., Ковалев Вит.В. Финансовый менеджмент: учебное пособие.- Москва: Проспект, 2010.-504 с. 